\title{
Agro-Based Sensor's Deployment for Environmental Anticipation: An Experimental Effort for Minimal Usage of Water within Agricultural Practices
}

\author{
Abhishek Khanna \\ Research Scholar, Thapar Institute of Engineering and Technology, Patiala, Punjab 147004, India.
}

\begin{abstract}
How to cite this paper: Abhishek Khanna. (2020) Agro-Based Sensor's Deployment for Environmental Anticipation: An Experimental Effort for Minimal Usage of Water within Agricultural Practices. International Journal of the Science of Food and Agriculture, 4(3), 219-236.

DOI: $10.26855 /$ ijfsa.2020.09.001
\end{abstract}

Received: June 8, 2020

Accepted: June 30, 2020

Published: July 14, 2020

*Corresponding author: Abhishek Khanna, Research Scholar, Thapar Institute of Engineering and Technology, Patiala, Punjab 147004, India. Email: abhikhanna@hotmail.com

\begin{abstract}
Agriculture plays an imperative role in the financial development of a country and provides the main source of income, food, employment specifically to the rural sector. In India, around $80 \%$ of the population is dependent upon agriculture as it is the primary source of income. Farmers make use of water for irrigation purpose and do not estimate its precise requirement. However, in reality, the requirement of water content is comparatively much lower than the one that is utilized. The irrigation system across the world can be more efficient if incorporation of automated systems is introduced, in order to estimate the precise amount of water requirement among fields. Hence, in order to overcome the concern of making minimal use of water for irrigation, Agro Based Decision Support System ( $A_{b} D S S$ ) has been proposed in the article. The proposed framework is proficient enough to help farmers correctly identify the precise need for water by their respective farms. The framework incorporates various agricultural sensors, i.e., soil moisture sensor, soil temperature sensor, and soil humidity sensor along with a computational cloud server, i.e., ThingSpeak. The proposed framework not only provides remote access for obtaining current farm parameters without being physically present at the site, reduces much of human energy, and results in increased efficiency. In addition, the water supply can be controlled remotely using the interface by making use of an electric valve and a relay installed on the nozzle.
\end{abstract}

\section{Keywords}

Soil moisture, Soil temperature, Agricultural sensors, Internet of Things (IoT), Wireless Sensor Networks

\section{Introduction}

Water is considered to be the most valuable resource in the world; however, its demand is always in an increasing phase across the world. It is considered important aspect of every possible means. It has been estimated that the amount of water sufficient to irrigate one hectare of the rice crop is the same that would cover the needs of 100 nomads with 450 heads of cattle over three years or 100 urban families over a two-year period [1]. Over the past few years, scarcity issues related to drought have been majorly prevalent. In agriculture, water is required in large quantities. Over and above the consumption of water for irrigation is one of the major problems under this domain. Although, there have been numerous techniques proposed by various researchers and academicians over the past few years to make minimal 
use of water. All the proposed techniques to control or save water's dissipation are either too expansive or beyond the conceptual knowledge of farmers. This dissipation problem not only causes water wastage but also becomes the root cause of the destruction of crops. The main sources of water for irrigation in Punjab are tube wells [2]. Apart from tube wells, canal water is also a prime source for irrigation. Even the groundwater level is going down very fast and it bears numerous side effects to soil health and to crops [3]. Hence, there is a dire need to develop an intelligent irrigation system to save water.

Numerous research articles over the years have proposed the usage of automatic irrigation systems. All the research articles have opted for different techniques to determine the existing condition of the soil. Based on observations, the precise amount of water required by the soil is determined [4-7]. In addition, the technology for the creation of networks between the sensors and the design of the control system was also highly debated by various experts [8], [9-12]. Apart from these techniques being expansive and beyond the knowledge of novice farmers, there are certainly other issues as well that are associated with the process of soil monitoring process, i.e., calibration, variability, and patchiness of rainfall water, etc. [13], [14]. In addition, excess usage of water has adverse effects on soil. Some of the adverse effects of excessive usage of water on soil include:

1) It inhibits the process of germination of seeds;

2) Roots do not grow properly in a waterlogged field;

3) Percentage of salinity increases in soil, due to the presence of salt in water;

4) Waterlogging with the field;

5) Hindrance in air communication for the plant's roots;

6) Reduction in soil temperature;

7) The shallowness of roots;

8) Land becomes marshy;

9) De-nitrogenization starts within the soil;

10) Shortage of soil nutritive elements and decrease in productivity.

In order to overcome the above-mentioned issues and to help novice farmers, there is a dire need of an intelligent monitoring and irrigation system that is less expansive and easy to handle, operate, and evaluate by novice farmers. Hence, the authors hereby propose a Requirement Based Decision Support System (RDBSS) that is relatively easy enough to operate and handle.

\section{Contribution to the research article}

In this paper, the most economical and cost-effective sensors have been incorporated for making observations. Furthermore, their advantages and disadvantages have been discussed by length. The system also makes use of external parameters for examining weather conditions, i.e., referring www.openweathermap.com for estimating precise weather conditions for the observed area [15]. Based on evaluations on various parameters, the process decision making comes underway with an aim to precisely irrigate the fields.

\subsection{Literature review}

Environment and its surrounds play an important role in the nourishment of any crop. The main factors that affect an agricultural zone are its soil properties, their ability to absorb and procure water within the soil, presence of moisture within the soil, humidity within the environment, soil temperature, the $\mathrm{pH}$ level of water, etc. Over the years, there have been numerous researches done on the above-said parameters to have firsthand information regarding various aspects associated to soil and later as per observation; evaluations are performed to undertake various agricultural activities. Various eminent researchers did some of the major contributions over the years are as under:

Hamad in his study highlighted the role of usage of smartphones for accessing agricultural information on various parameters and its advantages in the field of agriculture. 230 farmers across the region were interviewed and primary structured questionnaires were filled. The study highlighted that most of the farmers suggested the usage of smartphones for acquiring data on current farm conditions and relied on adopting newer agricultural techniques depicted on videos available in the field of PA [16].

Balducci in his study aimed at managing heterogeneous data coming from various datasets by virtue of sensory values. The study also depicts how productive companies (large scale or small scale, public or private) are in a race of increasing profitability by virtue of costs reduction, discovering appropriate ways to exploit data that are continuously recorded and made available can be the right choice to achieve subjective goals. The study suggested the usage of Neural network, Linear and Polynomial Regression Machine Learning models for decision-making and data handling [17].

Duhan emphasized on issues related to the perspective of the green revolution that resulted in blind usage of pesticides and chemical fertilizers that caused enormous loss to soil biodiversity and developed resistance against pathogens and pests in addition. They proposed the concept of Nano-encapsulated conventional fertilizers, herbicides and pesti- 
cides that helped in helps in slow and sustained release of nutrients and agrochemicals resulting in precise dosage among plants. Furthermore, the study also proposed the usage of Nanotechnology-based plant viral disease detection kits that proved to be very useful in speedy and early in the detection of viral diseases. The study highlighted a detailed explanation of the most commonly used Biosynthesis of nanoparticles and their vital use in the field of agriculture. Furthermore, the study depicted how the coated fertilizers could prove to be advantageous in resolving issues related to 102 soil microflora [18].

Severino in their study focused on impact of climate change in the field of agriculture. Furthermore, the authors highlighted the irregular use of water for irrigation purposes. Hence, an IoT based framework was proposed in the study to assess and control the environmental risks associated with the use of recycled water(s). The framework was designed had an autonomous network of sensors that collect data pertaining to soil moisture and the concentration of dissolved contaminants. The acquired data were used to assess the viability of water for irrigation by making use of drip irrigation technique for irrigating the root of the plants along with various other autonomous sensors by optimization of the irrigation scheduling. The main drawbacks were the proposed framework was site-specific and expensive, recycled water was used for irrigating the fields and water dynamics varied from location to location. Authors emphasized on the proper processing of the soil data within respective fields before incorporating the proposed framework [19].

Tuomisto in their study highlighted the shortcomings of environmental change, agricultural yields, and crop quality, and the critical pathways to future diets and health outcomes. Furthermore, the study depicts no quantitative models to test the impact of multiple environmental changes on nutrition and health outcomes. Hence, the authors proposed a framework that linked multiple interactions between environmental change, agricultural productivity and crop quality, population-level food availability, dietary intake, and health outcomes, with a prime focus on fruits and vegetables. The proposed framework focused on issues related to Socio-economic and societal factors, Environmental change stressors, Interventions and policies, Food system activities, Food and nutrition security and health and well-being outcomes. The study also visualized the problems that might be encountered while the adaptation of proposed framework among poor farmers [20].

Hellin highlighted the significant importance of water in the southeast area of Spain, in terms of its availability and cost. Hence, with respect to usage of water within the fields for performing various agricultural activities an Information and Communication Technologies (ICT) based framework has been proposed in the study that makes use of wireless nodes equipped that are powered by solar energy along with GPRS connectivity allowing its end-user (farmer) to analyze the information acquired through various agricultural sensors deployed within the fields for performing computations. The main aim was to generate maximum yield profits. The research article shed light on design, optimization, and development of a practical application to optimize water resources in irrigated agriculture by monitoring soil water status and the irrigation water [21].

Ojha's study depicted the significant importance of wireless sensor, devices and various other communication techniques that spurred newer directions of research in the field of agriculture. The study highlighted the potential use of WSN applications along with various challenges and issues associated with the deployment of agricultural sensors and devices for improved farming. Furthermore, designs of various WSN for agricultural applications were examined. A comparative analysis between Homogeneous and Heterogeneous architectures has been discussed in the research article. Emphasis was given on the usage of System on Chip (SoC) sensor nodes that target minimization of power consumption, cost, and easily deployable design. The research article also hosts the concept of identification of plant disease on four different parameters, i.e., Thrips, Rust, Bud Necrosis Virus (BNV) and Leaf Spot. However, the experimentation performed was on uni-seasonal climatic conditions. The authors further suggested more scope of simplification for existing frameworks [22].

Rameshaiah in their study explored the horizon of various kinds of fertilizers developed and acquaint with facts about the sensors in the same fields. The concept of Nano-technology was discussed in the study by length. The article aims to improve the ecosystem and help the farmers by using new-age technologies. It also aims to further benefit the agricultural engineering and technology in overcoming all the local myths and ethics decreasing the mega problems in the agriculture arena. However, the precise accuracy, natural reactions, effectiveness and cost for operation are some of the parameters that have not been discussed by a length in this article [23].

Soulis in his study highlighted the paramount importance of sensor's positioning within the field along with the accurate reading procedure and also emphasized on obtaining on accurate readings from various agricultural sensors based on precise deployment of sensors within the fields. The study made use of drip irrigation technique for irrigating the fields based on an existing mathematical model. The model evaluated the moisture readings gathered by various agricultural sensors and provided a decision regarding the precise amount of water required for irrigation. Lastly, the study also highlighted the ability of to the acquired mathematical model to serve a proactive tool for determining a detail investigation for various sensors and their positioning within the fields with an aim to attain an automated irrigation scheduling mechanism [24].

Lekshmi's research article emphasized in the paramount importance of evaluating the presence of soil moisture and 
other related parameters, i.e., agronomic, geological, ecological, biological and hydrological characteristics of the soil. The study focuses on evaluating the various techniques used for making observations that core influence during the cultivation process. Various soil moisture parameters have been categorized into three different levels based on various parameters. A major shortcoming in the research article is that the study is zone-specific and the influence of five other parameters like soil temperature, humidity, etc., have not been given adequate weight [25].

Mittelbach in their research article experimented with foremost common soil sensors, i.e., 10HS manufactured by Decagon Devices, United States, CS616 manufactured by Campbell Scientific, United States, SISOMOP manufactured by SMG University of Karlsruhe, Germany and TDR based TRIME-IT/-EZ manufactured by IMKO GmbH, Germany. All four sensors used for generating inputs related to various soil parameters. Later these values were compared widely to predict the soil behavior to make observations and then to take pro-active measures for minimal use of water for irrigation. The main aspect of the study was to assess the possibility of extension and calibration of all the sensors to have a precise idea regarding the behavior of soil under various environmental conditions. Furthermore, for each sensor, an actual evapotranspiration technique was used by applying and estimating a proper soil-water balance approach. The results were evaluated by comparing with a precise measurement value of a weighing lysimeter. The results obtained results were evaluated on Root Mean Square Difference (RMSD) and on Volumetric Water Content (VWC) and its anomalies. Lastly, the research article highlighted some major weaknesses of low-cost sensors, as the study suggested that low-cost sensors lacked sensitivity in certain soil moisture regimes. Moreover, the study stated that the low cost sensors were spurious and intrinsic to some type of instruments [26].

Zhang et al. proposed an evaluation of soil moisture content currently available on the testbed, to estimate the amount of water required for irrigating the fields, on the basis of readings made by captive soil moisture sensors. Furthermore, EC-5 sensor was used in the study for observing in order to acquire precise observations and to find the combined effect of soil temperature and salinity using Least Support Vector Machines on Matlab (LS-SVMlab) as the primary tool. Through experimentation, the authors effectively reduced the impact of soil temperature and salinity on the single sensor by determining the information-sharing range. Moreover, the detection precision and costs under different information-sharing radius. As a result, the proposed framework completely successfully calibrate the influence of soil temperature and salinity on sensors within multi-point network and provided an efficacious approach to determine the balance between the calibration accuracy of moisture sensor and the investment of agricultural production [27].

Xia proposed a revolutionary method in the field of precision agriculture by deploying various agricultural sensors for making experimentations within a red berry greenhouse. The proposed framework collected values pertaining to temperature, illumination, humidity, voltage and other parameters from the testbed, in order to perform evaluations. Transmission of observations was done to the remote location on a real-time basis. The proposed system also included a web platform that was integrated with Google Maps to notify the greenhouse (testbed) prevalent environmental status. The proposed framework also generated an alarming voice message along with an SMS alarm service. The warning messages were routed to from the proposed framework to farmer's registered mobile phone as a precautionary measure. Although the experimentation was low-cost, had scalability and provided real-time, stable and accurate service, the experimentation was only feasible to compare within a closed environment [28].

Vellidis in his study proposed real-time soil moisture and temperature measuring through sensors. The framework for initiating self-irrigation technique within cotton fields, therefore, used the observations. The entire process provided a closed-loop irrigation system where inputs from the smart sensor array determined timing and amount of water required for real-time site-specific irrigation applications, without human intervention [29].

Wang presented an overview of the most recent developments in various technologies and standards of various wireless sensors and their communications techniques. Various applications pertaining to wireless sensors, their networks and food production, i.e., Environmental monitoring, Weather monitoring, Machine-to-Machine (M2M) based process control, Facility Automation, and Traceability systems have been discussed in detail. The research article also highlights some of the most common shortcomings in the field of agriculture. Most important of them were the standardizations in the field of agriculture are still not up to the mark, early adopters of newer concepts are still facing issues in implementation, and Massive data generated by various agricultural sensors (wired/wireless), and have the potential to overwhelm all the existing issues. However, no proper actions are undertaken to take advantage of all their potentials, Existing Information Technology (IT) infrastructure, predominately wired communication structures, are simply not designed for pervasive inputs and require a significant overhaul. They make the existing system look more complex, Compatibility with legacy systems is not completely addressed. As a result, many existing users avoid the adoption of wireless products, Security, cost, complexity, lack of expertise, reliability on the wireless framework, etc., were some of the major concerns in the field of agriculture. The study also stated that the field of agriculture is yet to attain the status of "calm technology" [30].

As studied in this section, agricultural sensors play a vital role in this domain. Majority of research articles discussed in literature survey scale heights by virtue of the sensors. The next section highlights the significant importance of various agricultural sensors used in the agricultural domain. 


\subsection{Significance of agricultural sensors and other supporting devices}

Agricultural sensors play a vital role in making observations. There is a variety of sensors available, based on various precise requirements. Each sensor has a significant role to play. Sensor devices are selected according to requirements of its end-user. Some of the main parameters that are considered while selecting an agricultural sensor(s) have been depicted in Table 1.

Table 1. Parameters for selection of agricultural sensors

\begin{tabular}{cccc}
\hline Parameters & Soil Sensors & Weather Sensors & Plant Sensors \\
\hline Temperature & $*$ & $*$ & $*$ \\
Moisture & $*$ & - & - \\
Rain/Water flow & $*$ & - & - \\
Water level & $*$ & - & - \\
Conductivity & $*$ & - & - \\
Salinity & $*$ & $*$ & - \\
Humidity & - & $*$ & - \\
Atmospheric Pressure & - & $*$ & - \\
Wind speed & - & - & $*$ \\
Wind direction & - & - & $*$ \\
Photosynthesis & - & - & $*$ \\
Hydrogen & - & - & $*$ \\
Wetness & - & & \\
CO 2 & - & & \\
\hline
\end{tabular}

After identification of the requirement laid down by the end-user, the selected sensor is deployed within the testbed for making observations. The identified sensor can either partially placed on testbed or completely submerged beneath the soil surface for making observations. Either observations once recorded by the sensors can be stored on a data logger or they can be transmitted to the base station with the help of any communication device, either for storage or for analysis purpose. Apart from sensors, actuators are also deployed within the fields. Actuators are mechanical or electro-mechanical devices that provide either controlled or sometimes limited movements or positioning, which can be operated electrically, manually or by various fluids such as air, hydraulic, etc. Some of the various actuator types used in the field of agriculture are:

1) Electric Linear;

2) Fluid Power Linear;

3) Fluid Power Rotary;

4) Linear Chain Actuators;

5) Manual Linear;

6) Manual Rotary.

Based on the various parameters, three different agricultural sensors have been identified for the study that satisfies the basic needs to accomplish the objectives laid down for the experimentation purpose: Based on literature survey, it has been streamlined that it is very much essential to observe and evaluate the most common parameters associated with agriculture, i.e., soil moisture, soil humidity, soil temperature, etc. Hence, the authors have identified the following agricultural sensors in order to gather values for performing computations.

\subsubsection{Evana soil moisture sensor}

This device is capable of detecting moisture and humidity within the soil. Knowing the exact soil moisture conditions on their fields, not only the farmers are able to use less water to grow a crop, but they are also able to increase the yields and quality of the crop can be improved by the management of soil moisture during critical plant growth stages. This sensor is capable of estimating a precise reading between 0 to $45 \%$ of volumetric water content in soil and consumes a total power of $3 \mathrm{~mA} @ 5 \mathrm{VDC}$, whereas the operating temperature is between $-40^{\circ} \mathrm{C}$ to $+60^{\circ} \mathrm{C}$. Figure 1 depicts the pictorial representation of 5V - DC Evana soil moisture sensor, incorporated within the proposed study [31]. 


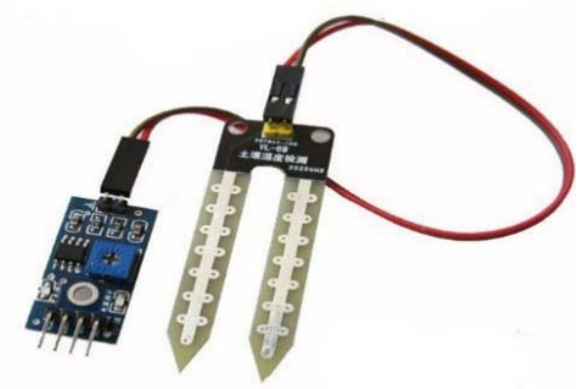

Figure 1. Evana Soil Moisture Sensor.

\subsubsection{Therm200 soil temperature sensor}

For making observations with respect to soil's temperature, THERM200-Soil Temperature Sensor Probe has been incorporated in proposed research. It has a temperature span from $-40^{\circ} \mathrm{C}$ to $85^{\circ} \mathrm{C}$. Its output varies between $0-3$ volts, where a $0 \mathrm{~V}$ represents $-40^{\circ} \mathrm{Cand} 3 \mathrm{~V}$ represents $85^{\circ} \mathrm{C}$ respectively [32]. Figure 2 depicts a pictorial representation of THERM200-Soil Temperature sensor used in proposed research.

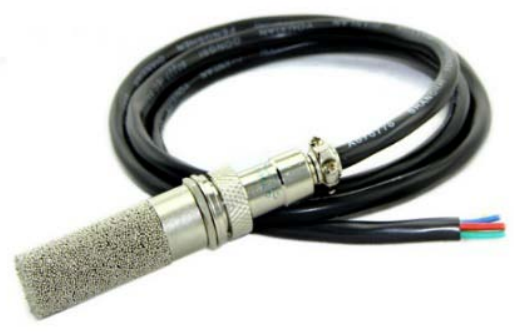

Figure 2. Therm200 Soil Temperature Sensor.

\subsubsection{DHT 11 Humidity and Temperature Sensor}

For making observations pertaining to humidity norms within the testbed, DH 11 humidity sensor incorporated in proposed research. Sensor's observational range varies from $20 \% \mathrm{RH}-90 \% \mathrm{RH}$, with an accuracy of ${ }_{-}^{+} \% \mathrm{RH}$. Itstemperature calculative range $0^{\circ} \mathrm{C}-50^{\circ} \mathrm{C}$, and the temperature accuracy varies between $\stackrel{ \pm}{-} 2^{\circ} \mathrm{C}$. Figure 3 depicts the pictorial representation of the DH 11 Humidity cum Temperature Sensor [33].

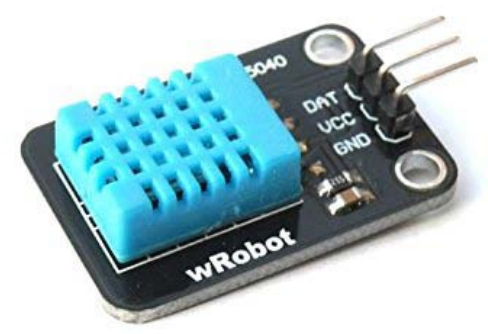

Figure 3. DHT 11 Humidity and Temperature Sensor.

\subsubsection{Arduino Uno}

An open-source electronics platform based on easy-to-use hardware and software. These devices are capable enough to be paired with a variety of sensors for reading inputs and can be used to have control over associated devices. Figure 4 depicts the pictorial representation of an Arduino Uno device. 


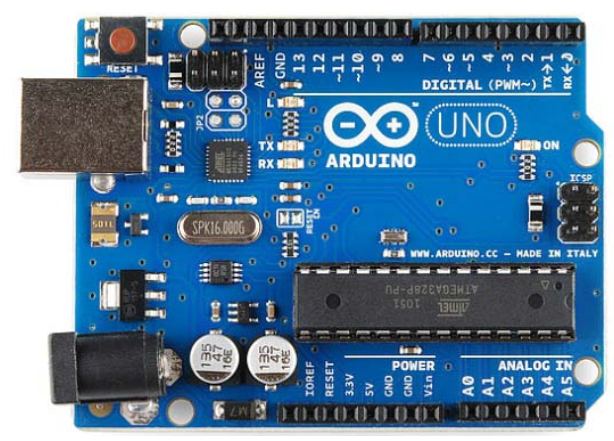

Figure 4. Arduino Uno.

\subsubsection{Zigbee}

An IEEE 802.15.4-based specification for a suite of high-level communication protocols used to create personal area networks within a small network [34]. Figure 5 depicts the pictorial representation of the incorporated device.

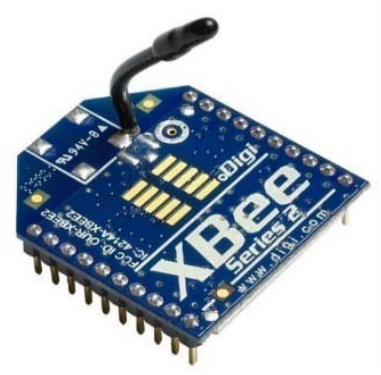

Figure 5. Zigbee.

\subsubsection{Network shield}

A network shield connects the Arduino device to the Internet with the help of built-in network card and an RJ45 cable. The device required 5V of electric current and has W5500 as an internal 32K buffer. The data transfer speed is 10/100 Mb. Figure 6 depicts the pictorial representation of the networking shield.

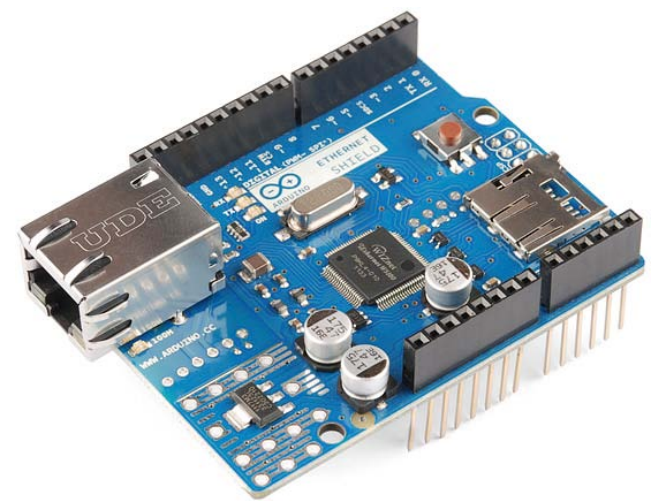

Figure 6. Network Shield.

\subsection{Identification of testbed for experimentation setup, data acquisition, and analysis}

The state of Punjab has been divided into three major regions, i.e., Majha, Doaba, and Malwa. As per reports of Economic and Statistical Organization, Govt. of Punjab, the water level in the state has drastically gone down over the past few years in all the three regions of the state [35]. Keeping in mind the existing standings of water level across the state, the authors have identified a testbed in the Majha region of Punjab, i.e., Patiala, is $12 \%$ below the required level, hence satisfying the basic objective of the study. All the experimental setup has been deployed on a kitchen garden and the experimentations were performed on cucumber vegetable in mind. Five random soil samples weighing 250 grams each were taken from various locations across the testbed, i.e., from all four corners and the center of the testbed for identification of soil's health status and also identify the type of soil so as to predict its behavior. As per the reports obtained, the soil turned out to be loamy in nature, which was ideal for agricultural use, i.e., it had a perfect combination 
of sand, soil, and clay by $47 \%, 31 \%$, and $22 \%$, respectively. In parallel, a verbal survey was also conducted through interaction mode with the farmers regarding the techniques adopted by them for irrigating the fields having the same cultivation as of testbed.

It was observed that the local farmers were a novice to the modern concepts of IoT based farming techniques and used generic practice for irrigating the fields, i.e., flood fill technique. According to farmers, for water-intensified crops like paddy, sugarcane, cucumber, etc., flood irrigation technique was adopted at least 2-3 times a day/acre. The area roughly required 20,000-22,000 liters of water consumption. However, as per farmers under slightly moist conditions in nearby areas the interval was increased by 3-5 a day as well. After interacting with the farmers, it has been concluded that there was adequate wastage of water within the fields. Hence, keeping the existing scenario the objective of research article was laid down, i.e., to design such a framework that makes use of the minimal amount of water for irrigation purposes.

In order to attain the objective of the study, a clear understanding towards soil's nature and behavior, the three basic sensors required for experimentation setup, i.e., Soil moisture sensor, Soil temperature sensor, Humidity and Temperature sensor as described in the concluding proportion of the previous section, i.e., Section 3 was deployed across the testbed. All the sensors were mounted on a Zigbee device within a distance of 15 meters to obtain the various parameters associated with soil [36], [37]. All the Zigbee(s) were paired to a master Zigbee (coordinator) that gathered observations from remote Zigbee(s) deployed within the fields. Lastly, the testbed was prepared for tillage and observations were recorded. As an extension to observational step, the data fetched by master Zigbee was transferred on a cloud server, i.e., ThingSpeak for a reference purpose to have any time access to the data being observed and for further performing prediction analysis.

\subsubsection{Collection and conversion of data acquired from Soil Moisture Sensor}

This section describes the stage where raw data is fetched by various agricultural sensors. The fetched values range between 0 and 1,023. As per specifications, each sensor has its own method to convert the raw data to be a voltage value. However, one constraint is that the sensor node is not always precise due to noises from the sensors. In order to remove the noises, the authors had applied the k-NN filtering technique to filter out the noises and smoothen the sensed data. Following formulation has been used to eliminate the noises for observed data.

$$
\mathrm{SN}\left[\mathrm{S}[\mathrm{SmS}, \mathrm{Hs}, \mathrm{Ts}] \frac{\text { Readings }}{T b, Z b r}\right] \frac{\text { Sensed Data }}{\text { Noise }} \mathrm{Mi}--\rightarrow \mathrm{Co} \frac{C D}{\text { Kalman Filtering }} K-N N \text { Filtering Technique } \frac{\text { Analysis }}{\mathrm{EU}} \frac{\text { Results }}{\text { Interface }}
$$

where SN: Sensor Network, S: Soil, Tb: Test Bed, SmS: Soilmoisture sensor, Hs: Humidity sensor, St: Temperature sensor, ZbR: Zigbee Router, ZbC: Zigbee Controller, Mi-Co: Micro-controller, BS: Base Station, CS: Cloud Server, CD: Cleansed Data, WS: Weather Station, EU: End User.

\subsubsection{Acquiring of Weather Data and its prediction}

The proposed system's framework also acquires the weather data from openweathermap.com, which includes historical, current, and forecasted weather conditions. This information is further used as a conditional input for making a proactive decision for irrigating the fields. The historical, as well as current weather data, has been used to model a decision tree for predicting the weather condition. The decision tree model is generated by using a machine-learning library for node j.s. Figure 7 shows our decision tree to predict the weather condition.

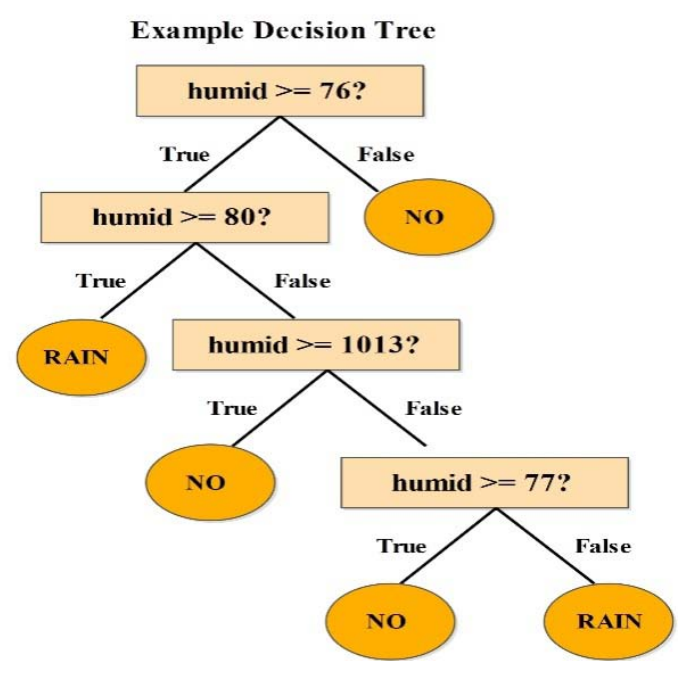

Figure 7. Decision tree for predicting the weather condition. 


\subsubsection{Decision-making criteria}

The predicted weather condition obtained from Step 4 and the smooth sensed data obtained from Step 2 is used to make a set of decision rules that the farmer should do as shown in Table 2.

Table 2. Decision rules for Decision-making process

\begin{tabular}{ccc}
\hline Results from Decision & Smooth sensed data & Decision to go \\
\hline "no rain” & Moisture $>=70 \%$ & "watering” \\
"no rain" & Moisture $>=70 \%$; Temperature $<=35^{\circ} \mathrm{C}$ & "watering” \\
"rain" or "storm" & Moisture $>=70 \%$ & "no watering required, it would rain \\
"rain" or "storm" & Moisture $>=70 \%$ & "no watering required, it would rain \\
\hline
\end{tabular}

Each condition 309 in Figure 7 has been derived from an optimal condition. The study becomes pragmatic in vision, as different plants will have a complete set of different decision criteria based on the optimal condition for each kind. The moisture threshold of cucumber is about $70 \%$. Hence, when the system detects that the moisture is below $70 \%$ and the predicted weather condition is "no rain", the system will automatically decide to irrigate the plants as the "Decision to do" with reference to Figure 7.

\subsection{ThingSpeak}

ThingSpeak is a cloud and an IoT platformthat allows us to store sensor data on the cloud, do analysis on that and develop IoT applications. It is a platform that provides applications that allow you to analyze and visualize your data in MATLAB, and then act according to the data received. The sensor data can be sent to ThingSpeak from Arduino using a Wi-Fi or Zigbee module, Raspberry-Pi, BeagleBone Black, and other hardware. ThingSpeak is an IoTplatform that uses channels and fields to store data sent from IoT based applications or devices. You create your channel and then the user can send (write) or retrieve (read) data to and from the channel using an API key, which is different from writing andreading. One can make n-number of channels that can be either public or private. By using the REST API calls, such as POST, GET, DELETE and PUT, you can create a channel and update your feed, update an existing channel, delete an information channel or delete a channel. You can also use the MQTT publishing method to update your news channel. Figure 8 depicts the field settings for ThingSpeak channel, Figure 9 depicts the API settings for ThingSpeak channel, and Figure 10 depicts the channel interface.

MATLAB analysis and visualization applications allow us to explore and view our channel data in a graphical way. ThingSpeak allows you to interactwith social networks, web services, and devices and provides API for it. One of the main advantages of ThingSpeak is that you can add weather forecasts to your project, which gives your project an advantage compared to live projects. It also provides activators such as tweeting when a condition occurs or simply running a MATLAB program as a trigger and many more.

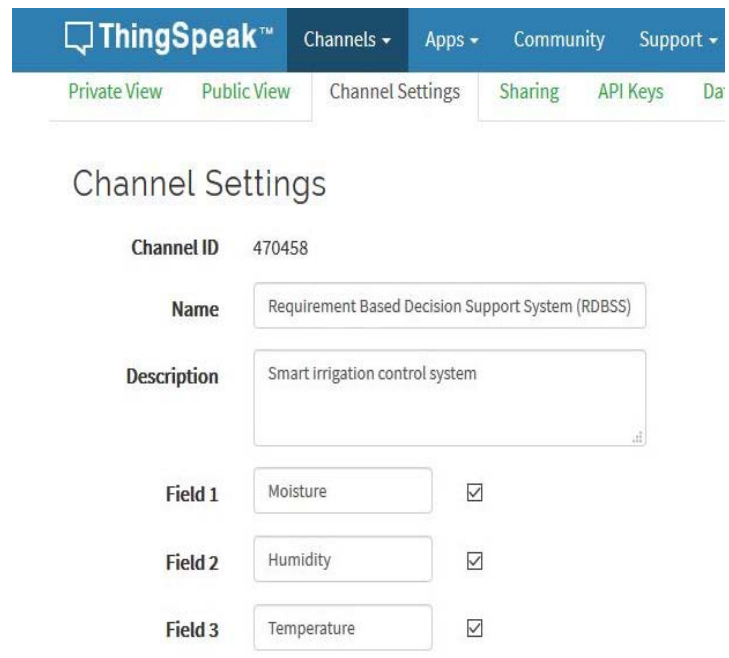

Figure 8. Field settings for ThingSpeak channel.

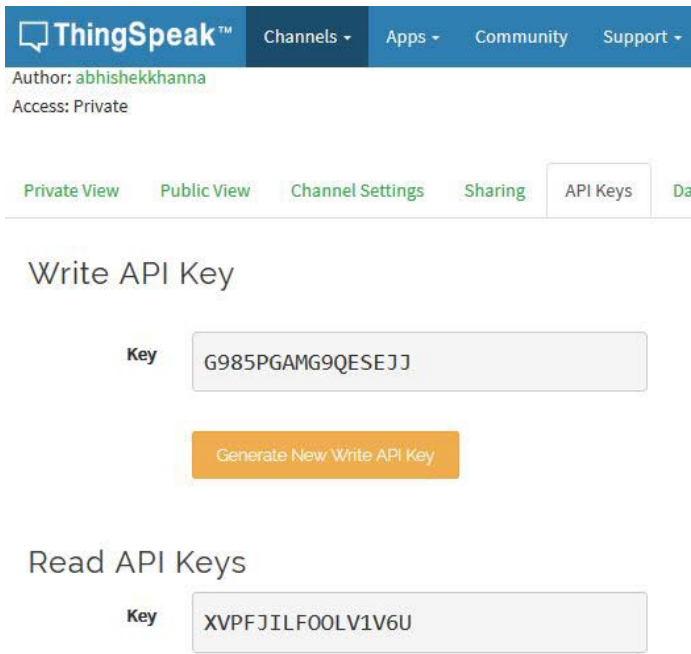

Figure 9. API key settings. 


\section{प ThingSpeak" channels- Appe- Communily Support-}

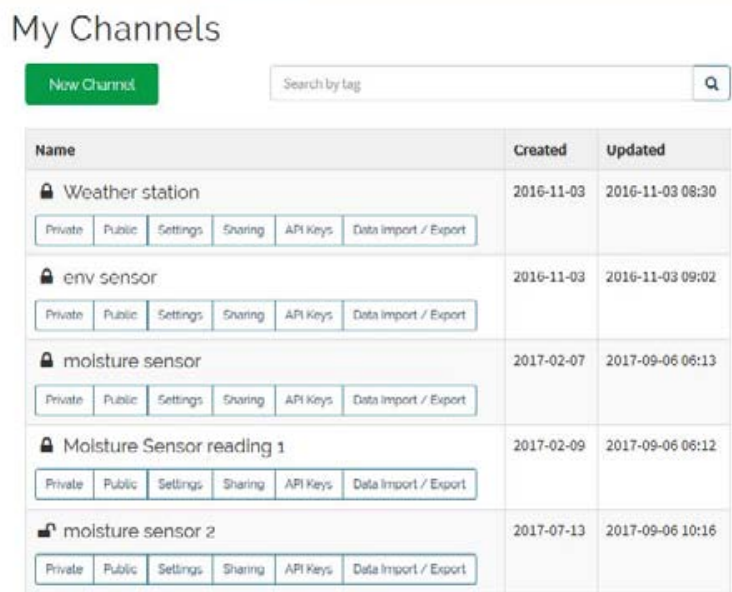

Figure 10. ThingSpeak channel selection webpage.

\subsubsection{Sending of data onto cloud server, i.e., ThingSpeak}

Furthermore, the observed data was sent onto the cloud server, i.e., ThingSpeak with the help of a networking shield that was mounted upon the Arduino Uno device. An advantage of uploading the observations to the cloud server is that it provides time-to-time updates of current farm situations without being physically present on-site. The farmer has the access to easily identify even the precise location of the field through the uploaded data by virtue of unique identification number given to each Zigbee router deployed within the field. Figure 11 depicts the pictorial representation of the graph generated by ThingSpeak cloud.

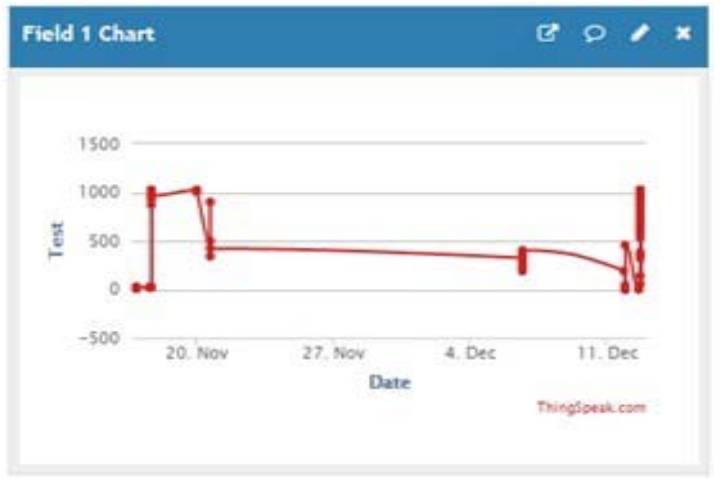

Figure 11. Graph build by ThingSpeak for different values of soil moisture.

In order to attain the objective an algorithm was incorporated within the study to make efficient use of water for irrigation purpose.

Algorithm 1. Automatic dispensing of water based on observations conducted by Agricultural Sensors

Require: Test Bed (Tb), Humidity sensor (Hs), Soil Moisture Sensor (SmS), Soil Temperature Sensor (Ts), Water flow sensor (Wfs) Flag $=1$, RR, RV, Dispense Water (Dw).

\section{begin}

select area $<-$ Tb

input sensor $1<-$ Hs, sensor $2<-$ SmS, sensor $3<-$ Ts , sensor $4<-$ Water flow sensor, flag $=1$

initialize $\mathrm{n}<-100 * 100$ (Test bed area)

for ( $\mathrm{i}=1$ to $\mathrm{n}$ ) do // for selecting the area

for $(j=1$ to $n)$ do $/ /$ for selecting the area

$\mathrm{X}<$ - sensed - values (sensor 1, sensor 2, sensor 3) //collecting sensors from data

fetch $\mathrm{Y}<$ - sensed weather (web-url) //getting weather information from www.openweathermap.com

$\mathrm{PR}<-$ combine $(\mathrm{X}, \mathrm{Y}) / /$ calculating all sensed values \& performing computations

store (PR)

if $(\mathrm{Hs} 1<40 \mathrm{~g} / \mathrm{m} 3) \mathrm{j} \mathrm{j}\left(\mathrm{WSmS}<38 \_\right.$) j j $(\mathrm{STS}<53.40 \mathrm{~g} / \mathrm{m} 3)$ then 
if (weather-condition == sunny ) then

activate sensor 4

dispense water $<-30$ minutes

deactivate sensor 4

flag ++

if (weather-condition == hazy) (weather-condition == cloudy ) then

activate sensor 4

flag ++

Dw $<-8$ minutes (sensor 4)

deactivate sensor 4

flag ++

else if (weather-condition == rainy) then

Dw $<-$ Nill

end if

Compute RV = water-sunny,

end if

end if

display RV

end for

end for

end

\subsection{Agro based Decision Support System ( $\left.A_{b} D S S\right)$ framework}

In order to overcome the basic issues related to the monitoring of wireless sensors and handling issues related to irrigation, the study proposes a Requirement Based Decision Support System (RDBSS) framework. The proposed framework composes of seven major elements:

1) Arduino Uno;

2) Evana soil moisture sensor;

3) Therm200 soil temperature sensor;

4) DHT 11 Humidity and Temperature sensor;

5) Zigbee module;

6) Cloud server, i.e., ThingSpeak;

7) Openweathermap.com (Open source domain for acquiring weather status).

In addition to the above, the framework also incorporates the use of openweathermap.com for estimating precise weather conditions for the experimental zone. Figure 12 depicts the conceptual working of the proposed framework. The sensors deployed within the fields record soil moisture, temperature, and humidity parameters. It further sends the data to ThingSpeak cloud platform for data analysis. This decides the action of turning on/off the irrigating valves. In return, Arduino Uno initiates a command that stops the water supply using an electric valve based on the decision. The values of the sensors are updated in ThingSpeak every 5-10 seconds plus the delay of Arduino communication.

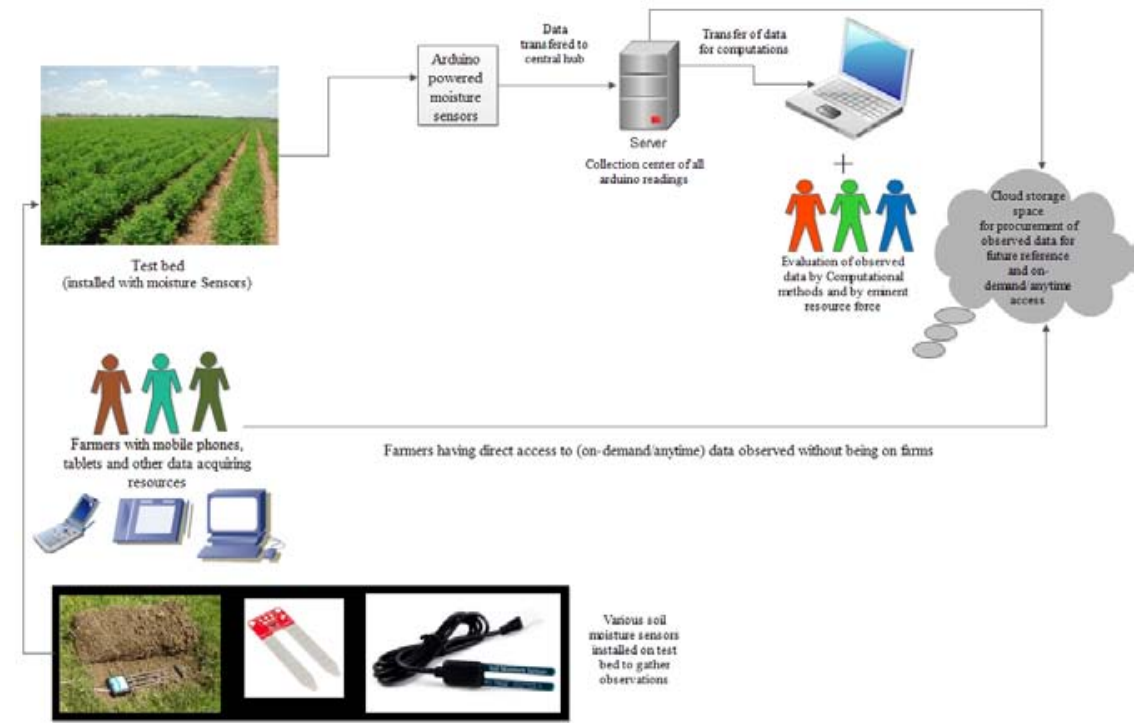

Figure 12. Conceptual working of the proposed framework. 


\section{Results}

Sensors were deployed onto the testbed and observations were gathered for a total of 5 months. A total of 10 feet $* 10$ feet area was taken under consideration for evaluations and testing purposes. Sensors were randomly deployed onto the fields. A total of 6 readings per hour with an interval of 10 minutes were taken, by uploading a sketch program in the Arduino Uno board. A total of 48 readings were taken throughout the day from all the three sensors, i.e., Soil moisture sensor, Soil temperature sensor, and Humidity sensor. Observations were conducted by deploying soil moisture sensors for recording moisture standings for the identified area. Minimum and maximum soil moisture recordings for the month of July, August, September, October and November were between $518 \mathrm{~g} / \mathrm{m}^{3}-770 \mathrm{~g} / \mathrm{m}^{3}, 512 \mathrm{~g} / \mathrm{m}^{3}-770 \mathrm{~g} / \mathrm{m}^{3}$, 518 $\mathrm{g} / \mathrm{m}^{3}-770 \mathrm{~g} / \mathrm{m}^{3}, 512 \mathrm{~g} / \mathrm{m}^{3}-770 \mathrm{~g} / \mathrm{m}^{3}$ and $512 \mathrm{~g} / \mathrm{m}^{3}-770 \mathrm{~g} / \mathrm{m}^{3}$, respectively. An average reading for the day was calculated based on the entire 48 readings. Based on the average calculation of readings, Figure 13 depicts bar graph observations for Soil Moisture (average/day) from 1/July/18 to 30/November/18.

Observations were conducted by deploying soil temperature sensors for recording temperature standings for the identified area. Minimum and maximum soil moisture recordings for the month of July, August, September, October and November were between $26.09^{\circ} \mathrm{C}-27.98^{\circ} \mathrm{C}, 26.19^{\circ} \mathrm{C}-27.69^{\circ} \mathrm{C}, 26.01^{\circ} \mathrm{C}-26.25^{\circ} \mathrm{C}, 25.61^{\circ} \mathrm{C}-26.10^{\circ} \mathrm{C}$ and $24.93^{\circ} \mathrm{C}-25.88^{\circ} \mathrm{C}$, respectively. An average reading for the day was calculated based on the entire 48 readings. Based on the average calculation of readings, Figure 14 depicts bar graph observations for Soil Temperature (average/day) from 1/July/18 to30/November/18.

Similarly, observations were conducted by deploying humidity sensors for recording humidity standings for the identified area. Minimum and maximum soil moisture recordings for the month of July, August, September, October and November were between $36.40 \mathrm{~g} / \mathrm{m}^{3}-38.90 \mathrm{~g} / \mathrm{m}^{3}, 37.10 \mathrm{~g} / \mathrm{m}^{3}-39.10 \mathrm{~g} / \mathrm{m}^{3}, 26.00 \mathrm{~g} / \mathrm{m}^{3}-37.30 \mathrm{~g} / \mathrm{m}^{3}, 33.50 \mathrm{~g} / \mathrm{m}^{3}-36.10 \mathrm{~g} / \mathrm{m}^{3}$ and $32.10 \mathrm{~g} / \mathrm{m}^{3}-36.40 \mathrm{~g} / \mathrm{m}^{3}$, respectively. An average reading for the day was calculated based on the entire 48 readings. Based on the average calculation of readings, Figure 15 depicts bar graph observations for Humidity (average/day) from 1/July/18 to 30/November/18.

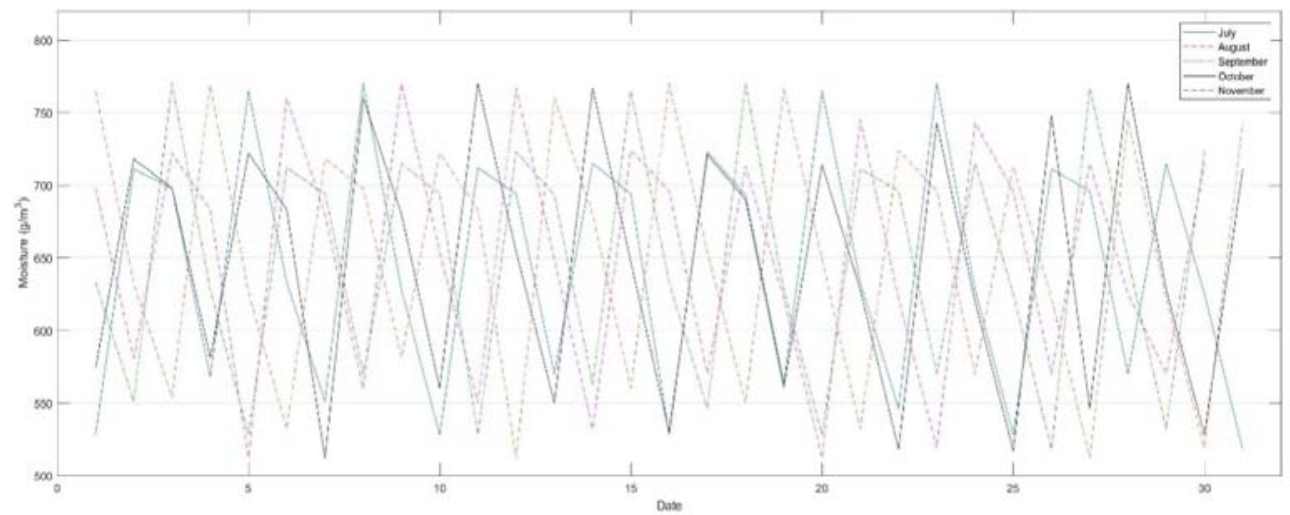

Figure 13. Average soil moisture readings for July-Nov’19.

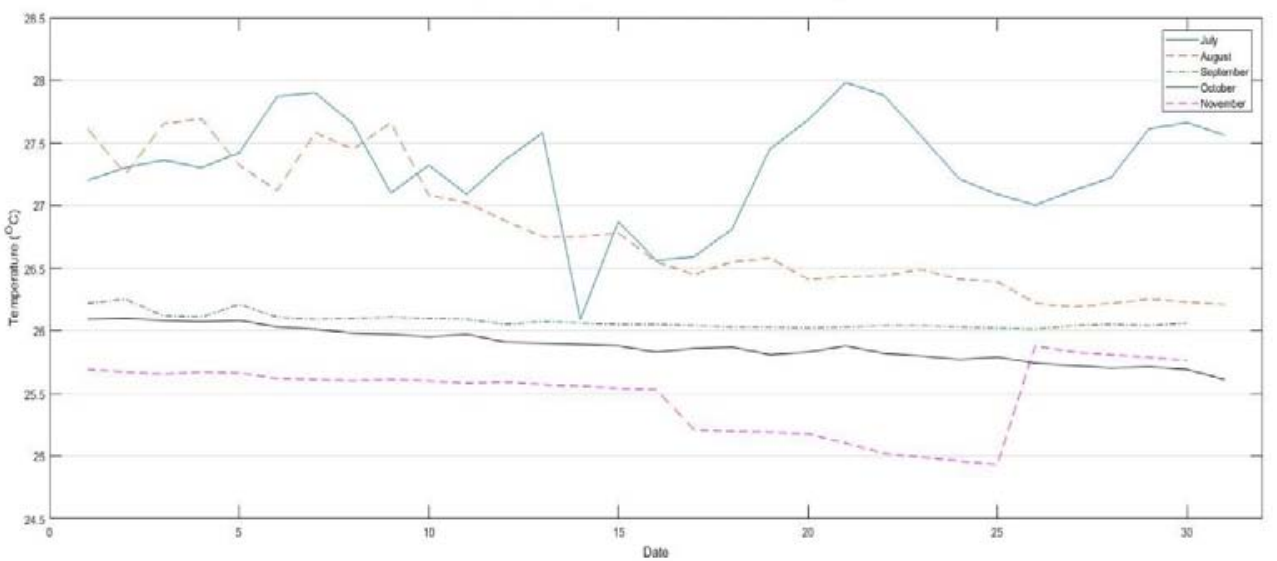

Figure 14. Average soil temperature readings for July-Nov'19. 


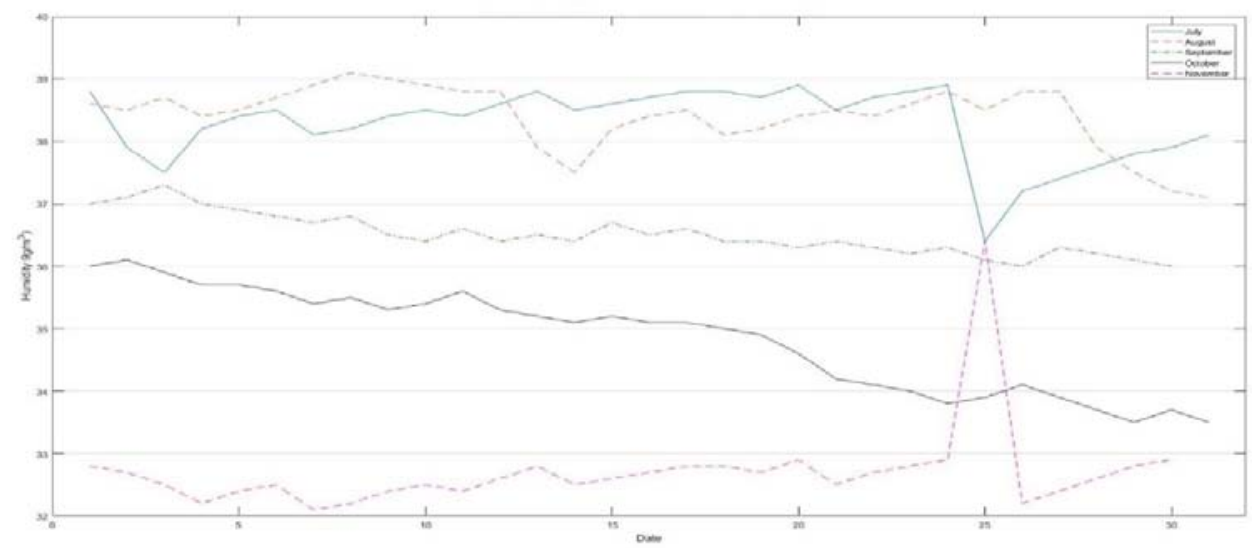

Figure 15. Average soil humidity readings for July-Nov'19.
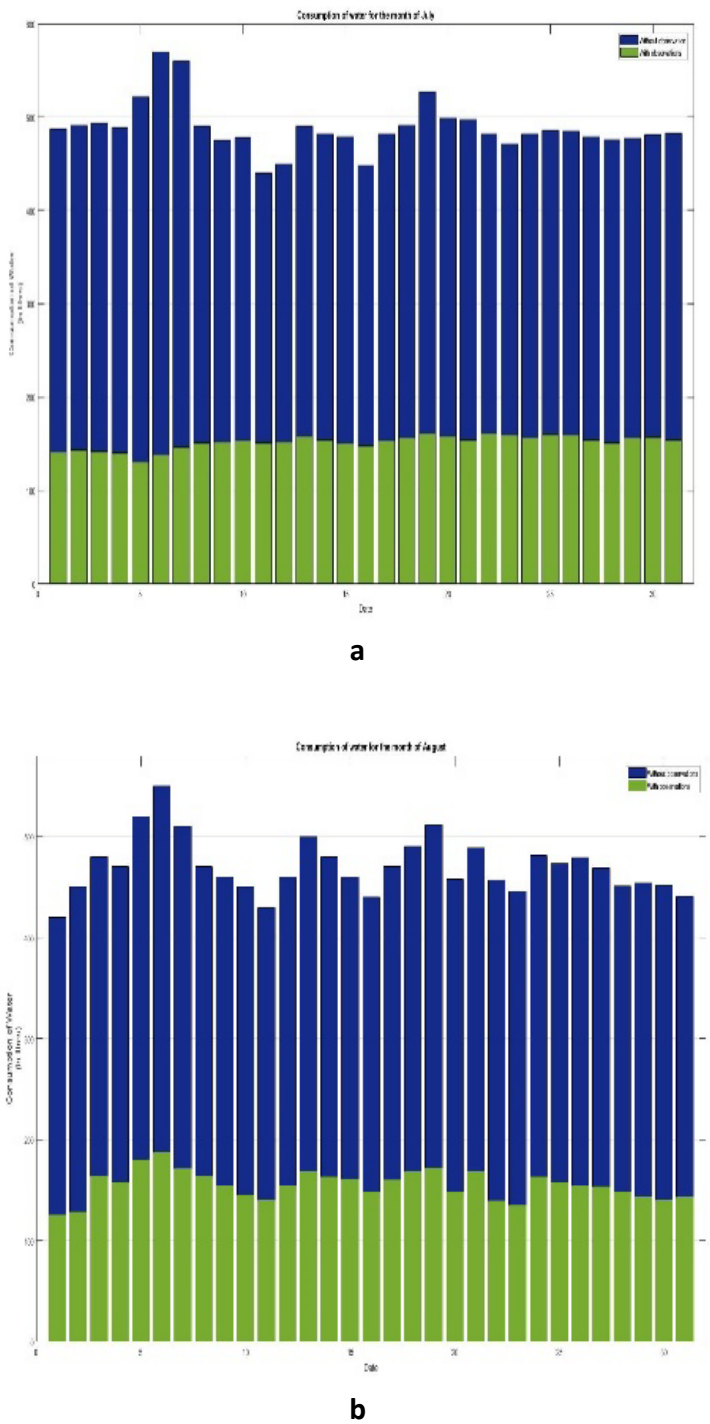

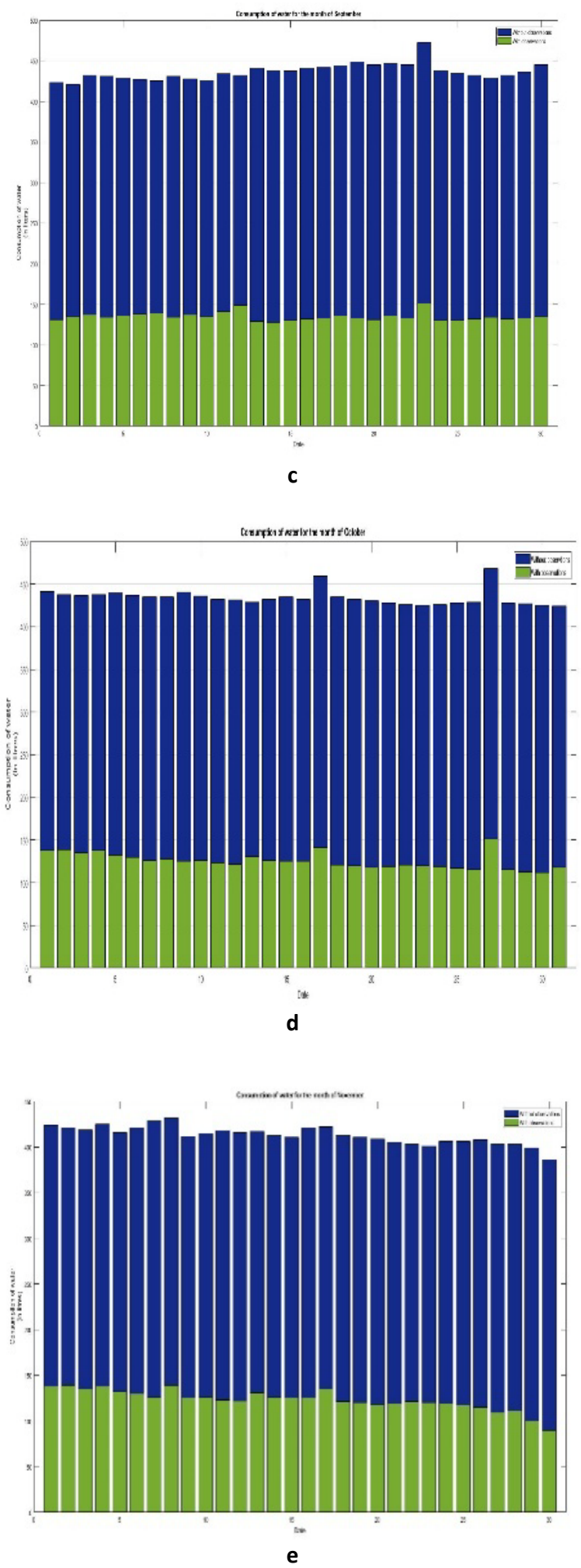

Figure 16. Consumption of water with and without observations from July-Nov'19.

Furthermore, these average readings were evaluated along with the data acquired from a weather-predicting website (www.openweathermap.com) to have a more precise as well as accurate dataset for proper evaluation of predicting the precise amount of water for irrigating the testbed. Before preparing the proposed model a precise estimation of actual 
water consumption was taken into consideration (without the usage of sensors), where the farmer was asked to irrigate the testbed with different dimensions some days prior to commencement of experimentations. After making observations on various parameters, i.e., soil temperature, moisture, and atmospheric humidity, it has been concluded that soil properties vary from location to location. By deploying sensors on the testbed, observations were made and accordingly, water was dispensed on the testbed. On the basis of mathematical evaluations, it has been conducted that on an average only $31.58 \%, 32.90 \%, 30.91 \%$, 28.87\%, and $28.77 \%$ liters of water has been consumed for July, August, September, October, and November, respectively. Figure 16a-16e depicts the consumption of water with and without observations from July'19-November'19.

\subsection{Comparative analysis of the proposed framework and its advantages with other related studies}

In an order to validate the existing study, it has been compared with a number of research articles of the same domain over the past few years. Some of the major contributions in the field of agriculture have been depicted in Table 3.

In the majority of research articles referred in Table 3, the main focus has been on retaining the maximum amount of water or using newer techniques for irrigating fields, with one focus in mind that is to make use of the minimum amount of water. The existing study has been compared with every research article mentioned in Table 3 and expectedly the current research leads ahead in terms of conceptual implementation, usage of new-age devices for making observations and using one of the most reliable technique, i.e., K-NN machine learning algorithm for making predicting the soil behavior in advance. According to the observed results, either the data could be fed to the system or threshold values could be altered in advance so that the irrigating system would perform according to predicted values.

Table 3. Comparative analysis of existing study with other proposed framework of the same domain

\begin{tabular}{|c|c|c|c|c|}
\hline $\begin{array}{l}\text { Citation\& Year } \\
\text { of Publication }\end{array}$ & Methodology proposed & Research focus & Outcomes & $\begin{array}{c}\text { Advantage of existing } \\
\text { study }\end{array}$ \\
\hline $\begin{array}{c}{[39]} \\
\& \\
2017\end{array}$ & $\begin{array}{c}\text { An irrigation system that } \\
\text { focuses } \\
\text { on adequate applying } \\
\text { of water at the root zone }\end{array}$ & $\begin{array}{c}\text { Enhancing sprinkler irriga- } \\
\text { tion } \\
\text { technique, } \\
\text { Less consumption of water }\end{array}$ & $\begin{array}{l}\text { Non-uniformity in sprinkler } \\
\text { irrigation }\end{array}$ & $\begin{array}{c}\text { Appropriate irrigation } \\
\text { within field without } \\
\text { using any irrigating devices, } \\
\text { Avoiding overhead } \\
\text { costs }\end{array}$ \\
\hline $\begin{array}{c}{[40]} \\
\& \\
2017\end{array}$ & $\begin{array}{l}\text { An integrated modeling } \\
\text { approach }\end{array}$ & - & Variable-rate integration & $\begin{array}{c}\text { Crop specific irrigation } \\
\text { ontology }\end{array}$ \\
\hline $\begin{array}{l}{[41]} \\
\& \\
2017\end{array}$ & $\begin{array}{l}\text { Embedded and micro } \\
\text { controller systems }\end{array}$ & $\begin{array}{l}\text { Irrigating kitchen garden/ } \\
\text { lawns as per requirements }\end{array}$ & $\begin{array}{c}\text { Proper estimation of water- } \\
\text { ing } \\
\text { demands }\end{array}$ & $\begin{array}{l}\text { Automatic control system } \\
\text { for the proposed system } \\
\text { is based on conceptual } \\
\text { concepts }\end{array}$ \\
\hline $\begin{array}{c}{[42]} \\
\& \\
2017\end{array}$ & $\begin{array}{l}\text { Multi-threshold MT - } \\
\text { based technique }\end{array}$ & Water-saving in agriculture & $\begin{array}{l}\text { Autonomous wireless } \\
\text { system }\end{array}$ & $\begin{array}{l}\text { Autonomous wireless } \\
\text { 4the system, Daily report } \\
\text { generation }\end{array}$ \\
\hline $\begin{array}{c}{[43]} \\
\& \\
2017\end{array}$ & $\begin{array}{c}\text { Validation experimentation } \\
\text { of } 2 \text { sensors, i.e., Soil } \\
\text { moisture tension sensor } \\
\text { and Soil moisture sensor }\end{array}$ & $\begin{array}{c}\text { Evaluation of water reten- } \\
\text { tion } \\
\text { within fields }\end{array}$ & $\begin{array}{c}\text { Dependency upon intuition } \\
\text { and experience to } \\
\text { determine when and how } \\
\text { much water should be } \\
\text { provided }\end{array}$ & $\begin{array}{l}\text { IoT based automated } \\
\text { process requires least } \\
\text { amount of farmer's interven- } \\
\text { tion } \\
\text { for decision } \\
\text { making }\end{array}$ \\
\hline $\begin{array}{c}{[21]} \\
\& \\
2015\end{array}$ & $\begin{array}{l}\text { ICT concepts for transfer- } \\
\text { ring } \\
\text { of observed data for } \\
\text { manual evaluations }\end{array}$ & Optimal utilization of water & $\begin{array}{l}\text { Technical challenges } \\
\text { addressed in terms of } \\
\text { WSN's and GSM/GPRS } \\
\text { network communications }\end{array}$ & $\begin{array}{l}\text { Complex devices like } \\
\text { GSM/GPRS not used in } \\
\text { existing study }\end{array}$ \\
\hline $\begin{array}{c}{[44]} \\
\& \\
2015\end{array}$ & $\begin{array}{l}\text { Linear programming } \\
\text { model for performing } \\
\text { irrigation purposes }\end{array}$ & $\begin{array}{c}\text { Diversification plan for } \\
\text { achieving water sustainabil- } \\
\text { ity }\end{array}$ & $\begin{array}{l}\text { Water utilized as per re- } \\
\text { quirement }\end{array}$ & $\begin{array}{c}\text { No complex mechanism } \\
\text { used }\end{array}$ \\
\hline $\begin{array}{l}{[45]} \\
\& \\
2014\end{array}$ & $\begin{array}{l}\text { Highlighted the modes of } \\
\text { gathering water in scarce } \\
\text { areas }\end{array}$ & $\begin{array}{l}\text { Getting water available } \\
\text { for agricultural purposes }\end{array}$ & $\begin{array}{l}\text { Increased overhead costs } \\
\text { and no concrete solution } \\
\text { to resolve the issue of water } \\
\text { scarcity }\end{array}$ & $\begin{array}{c}\text { Consumption of water as } \\
\text { per requirement }\end{array}$ \\
\hline $\begin{array}{c}{[46]} \\
\& \\
2010\end{array}$ & $\begin{array}{c}\text { Smart Irrigation Control } \\
\text { System }\end{array}$ & Precise water requirement & $\begin{array}{c}\text { Automatic electronic hydro } \\
\text { valve }\end{array}$ & $\begin{array}{c}\text { Auto irrigation and control } \\
\text { the mechanism, Data acqui- } \\
\text { sition } \\
\text { and repository } \\
\text { for further references }\end{array}$ \\
\hline $\begin{array}{c}{[47]} \\
\& \\
2004\end{array}$ & - & Crop Water Productivity & $\begin{array}{l}\text { Irrigation performed as } \\
\text { per the kind of yield }\end{array}$ & $\begin{array}{l}\text { Irrigation water inputs as } \\
\text { per requirements }\end{array}$ \\
\hline
\end{tabular}

According to the mathematical computations, averagely for a month specifically on testbed 1,260 liters/month of wa- 
ter has been saved. Since the cucumber takes a span of $3-4$ weeks to grow properly, out of which for averagely 2-3.5months it requires water extensively. As per the calculations based on results obtained from the practical implementation of a research article, researchers were able to save 6,384 liters of water in 5 months. The amount of water-saving extends as the evaluation increases from testbed to actual dimensions of the farm.

\section{Conclusion}

Agricultural monitoring is very much needed at all times to reduce human intervention and water usage. Furthermore, it is very much important to understand the soil parameters before performing agricultural activities. Over the years, many systems have been proposed and developed by deploying various sensors for monitoring purposes within the fields. In our research, it has been concluded that soil values vary from location to location. Now with the advent of Machine-to-Machine (M2M) communication, which involves devices to communicate among themselves in taking action, we hereby have developed a Agro based Decision Support System ( $A_{b} D S S$ ) that supports an automated irrigation module. Observations are made and transmitted for computations. Based on the observed valuespre-determined module, decisions are made and control signals are sent to actuators that irrigate the fields according to the requirements. The water consumption among fields is way less as compared to present water consumption statistics among other fields, depicting that the usage of water can be diminished. This proposed system was found to be feasible and cost-effective for optimizing water resources for field-related activities. Furthermore, as an extension, the Internet link allows supervision through mobile telecommunication devices, such as a smartphone, tablet, personal computer, etc.

In the future, Agro-baed Decision Support System ( $A_{b} D S S$ ) can be adjusted to cater to a variety ofcrop needs and would require minimal upgrade and maintenance. Furthermore, the proposed system can be hyperextended for practicing fertilization part as well. The proposed system can be designed to make decisions on identifying correct fertilizer for the field in order to maintain proper growth and avoid adverse effects on crops. Lastly, the data acquired by various sensors from agricultural data can also be procured for training purposes and for future implementation on a variety of crops as well.

\section{Conflict of Interest}

There is no conflict of interest.

\section{References}

[1] S. Bhuiyan, M. Sattar, M. Khan. (1995). Improving water use efficiency in rice irrigation through wet-seeding. Irrigation Science, 16(1): 1-8.

[2] A. D. Roy, T. Shah. (2002). Socio-ecology of groundwater irrigation in India, Intensive use of groundwater challenges and opportunities (2002): 307-335.

[3] R. Rattan, S. Datta, P. Chhonkar, K. Suribabu, A. Singh. (2005). Long-term impact of irrigation with sewage effluents on heavy metal content in soils, crops and groundwatera case study. Agriculture, Ecosystems \& Environment, 109(3-4): 310-322.

[4] L. Richards, L. Weaver. (1944). Moisture retention by some irrigated soils as related to soil moisture tension. Journal of Agricultural Research, 69(6): 215-235.

[5] N. Edlefsen, A. Anderson, et al. (1943). Thermodynamics of soil moisture. Hilgardia, 15(2): 31-298.

[6] O. T. Denmead, R. H. Shaw. (1962). Availability of soil water to plants as affected by soil moisture content and meteorological conditions 1. Agronomy Journal, 54(5), 385-390.

[7] G. S. Campbell, M. D. Campbell. (1982). Irrigation scheduling using soil moisture measurements: theory and practice. Advances in Irrigation, 1(1982): 25-42.

[8] N. Bhawarkar, D. Pande, R. Sonone, M. Aaquib, P. Pandit, P. Patil. (2014). Literature review for automated water supply with monitoring the performance system. International Journal of Current Engineering and Technology, 4(5): 3328-3331.

[9] Z. Zhang. (2004). Investigation of wireless sensor networks for precision agriculture. in: 2004 ASAE Annual Meeting, American Society of Agricultural and Biological Engineers, 2004, p. 1.

[10] S.-e. Yoo, J.-e. Kim, T. Kim, S. Ahn, J. Sung, D. Kim. (2007). A²S: Automated Agriculture System Based on WSN, in: Consumer Electronics, 2007. ISCE 2007. IEEE International Symposium on, IEEE, 2007, pp. 1-5.

[11] A. Z. Abbasi, N. Islam, Z. A. Shaikh, et al. (2014). A review of wireless sensors and networks' applications in agriculture, Computer Standards \& Interfaces 36(2): 263-270.

[12] X. Li, Y. Deng, L. Ding. (2008). Study on precision agriculture monitoring framework based on WSN, in: Anti-counterfeiting, Security and Identification, 2008. ASID 2008. 2nd International Conference on, IEEE, 2008, pp. 182-185.

[13] V. I. Adamchuk, J. Hummel, M. Morgan, S. Upadhyaya. (2004). On-the-go soil sensors for precision agriculture, Computers and electronics in agriculture, 44(1): 71-91. 
[14] M. Sivapalan, R. A.Woods. (1995). Evaluation of the effects of general circulation models' subgrid variability and patchiness of rainfall and soil moisture on land surface water balance fluxes, Hydrological Processes, 9(5-6): 697-717.

[15] [link]URL https://openweathermap.org/city/1260107.

[16] M. A. Hamad, M. E. S. Eltahir, A. E. M. Ali, A. M. Hamdan. Efficiency of using smart-mobile phones in accessing agricultural information by smallholder farmers in north kordofan-sudan, Available at SSRN 3240758.

[17] F. Balducci, D. Impedovo, G. Pirlo. (2018). Machine learning applications on agricultural datasets for smart farm enhancement, Machines, 6(3): 38.

[18] J. S. Duhan, R. Kumar, N. Kumar, P. Kaur, K. Nehra, S. Duhan. (2017). Nanotechnology: The new perspective in precision agriculture, Biotechnology Reports, 15(2017): 11-23.

[19] G. Severino, G. DUrso, M. Scarfato, G. Toraldo. (2018). The IoT as a tool to combine the scheduling of the irrigation with the geostatistics of the soils, Future Generation Computer Systems.

[20] H. L. Tuomisto, P. F. Scheelbeek, Z. Chalabi, R. Green, R. D. Smith, A. Haines, A. D. Dangour. (2017). Effects of environmental change on agriculture, nutrition and health: A framework with a focus on fruits and vegetables, Wellcome open research 2.

[21] H. Navarro-Hell'in, R. Torres-Sánchez, F. Soto-Valles, C. Albaladejo-Pérez, J. A. Ló́pez-Riquelme, R. Domingo- Miguel. (2015). A wireless sensors architecture for efficient irrigation water management, Agricultural Water Management, 151(2015): 64-74.

[22] T. Ojha, S. Misra, N. S. Raghuwanshi. (2015). Wireless sensor networks for agriculture: The state-of-the-art in practice and future challenges, Computers and Electronics in Agriculture, 118(2015): 66-84.

[23] G. Rameshaiah, J. Pallavi, S. Shabnam. (2015). Nano fertilizers and nano sensors—an attempt for developing smart agriculture, Int J Eng Res Gen Sci, 3(1): 314-320.

[24] K. X. Soulis, S. Elmaloglou, N. Dercas. (2015). Investigating the effects of soil moisture sensors positioning and accuracy on soil moisture based drip irrigation scheduling systems, Agricultural Water Management, 148: 258-268.

[25] S. L. SU, D. Singh, M. S. Baghini. (2014). A critical review of soil moisture measurement, Measurement, 54(2014): 92-105.

[26] H. Mittelbach, I. Lehner, S. I. Seneviratne. (2012). Comparison of four soil moisture sensor types under field conditions in Switzerland, Journal of Hydrology 430(2012): 39-49.

[27] R.-b. Zhang, J.-j. Guo, L. Zhang, Y.-c. Zhang, L.-h. Wang, Q. Wang. (2011). A calibration method of detecting soil water content based on the information-sharing in wireless sensor network, Computers and Electronics in Agriculture, 76(2): 161-168.

[28] J. Xia, Z. Tang, X. Shi, L. Fan, H. Li. (2011). An environment monitoring system for precise agriculture based on wireless sensor networks, in: Mobile Ad-hoc and Sensor Networks (MSN), 2011 Seventh International Conference on, IEEE, 2011, pp. 28-35.

[29] G. Vellidis, M. Tucker, C. Perry, C. Kvien, C. Bednarz. (2008). A real-time wireless smart sensor array for scheduling irrigation, Computers and electronics in agriculture, 61(1): 44-50.

[30] N. Wang, N. Zhang, M. Wang. (2006). Wireless sensors in agriculture and food industry recent development and future perspective, Computers and electronics in agriculture, 50(1): 1-14.

[31] B. Domenico, J. Caron, E. Davis, S. Nativi, L. Bigagli. (2006). Galeon: standards-based web services for interoperability among earth sciences data systems, in: Geoscience and Remote Sensing Symposium, 2006. IGARSS 2006. IEEE International Conference on, IEEE, 2006, pp. 313-316.

[32] V. M. Quan, G. S. Gupta, S. Mukhopadhyay. (2011). Review of sensors for greenhouse climate monitoring, in: Sensors Applications Symposium (SAS), 2011 IEEE, IEEE, 2011, pp. 112-118.

[33] N. Tianlong. (2010). Application of single bus sensor dht11 in temperature humidity measure and control system [J], Microcontrollers \& Embedded Systems, 6(2010): 026.

[34] Z. Alliance. What is zigbee?

[35] G. of Punjab. Economic and Statistical Organisation, Govt. of Punjab, publication No. 954 Edition.

[36] R. Morais, M. A. Fernandes, S. G. Matos, C. Sero^dio, P. Ferreira, M. Reis. (2008). Azigbeemulti-poweredwireless acquisition device for remote sensing applications in precision viticulture, Computers and electronics in agriculture, 62(2): 94-106.

[37] M. Keshtgari, A. Deljoo. (2012). A wireless sensor network solution for precision agriculture based on zigbee technology, Wireless Sensor Network, 4(1): 25.

[38] S. Salvi, S. F. Jain, H. Sanjay, T. Harshita, M. Farhana, N. Jain, M. Suhas. (2017). Cloud based data analysis and monitoring of smart multi-level irrigation system using iot, in: I-SMAC (IoT in Social, Mobile, Analytics and Cloud) (I-SMAC), 2017 International Conference on, IEEE, 2017, pp. 752-757.

[39] R. O. Darko, Y. Shouqi, L. Junping, Y. Haofang, Z. Xingye. (2017). Overview of advances in improving uniformity and water use efficiency of sprinkler irrigation, International Journal of Agricultural and Biological Engineering, $10(2): 1$.

[40] R. Gonz'alezPerea, A. Daccache, J. Rodr'1guezD'iaz, E. Camacho Poyato, J. W. Knox. (2018). Modelling impacts of precision 
irrigation on crop yield and in-field water management.

[41] A. Tyagi, N. Gupta, J. Navani, M. R. Tiwari, M. A. Gupta. (2017). Smart irrigation system, International Journal for Innovative Research in Science \& Technology, 3(10).

[42] F. Viani, M. Bertolli, M. Salucci, A. Polo. (2017). Low-cost wireless monitoring and decision support for water saving in agriculture, IEEE Sensors Journal, 17(13): 4299-4309.

[43] T. Yamazaki, K. Miyakawa. (2017). Soil moisture sensing experiments for water management in pear fields, in: Proceedings of the 6th International Conference on Informatics, Environment, Energy and Applications, ACM, 2017, pp. 56-59.

[44] B. Kaur, K. Vatta, R. Sidhu. (2015). Optimising irrigation water use in Punjab agriculture: Role of crop diversification and technology, Indian Journal of Agricultural Economics, 70(3): 307.

[45] L. Levidow, D. Zaccaria, R. Maia, E. Vivas, M. Todorovic, A. Scardigno. (2014). Improving water-efficient irrigation: Prospects and difficulties of innovative practices, Agricultural Water Management, 146(2014): 84-94.

[46] K. Xiao, D. Xiao, X. Luo. (2010). Smart water-saving irrigation system in precision agriculture based on wireless sensor network, Transactions of the Chinese Society of Agricultural Engineering, 26(11): 170-175.

[47] S. J. Zwart, W. G. Bastiaanssen. (2004). Review of measured crop water productivity values for irrigated wheat, rice, cotton and maize, Agricultural water management, 69(2): 115-133. 